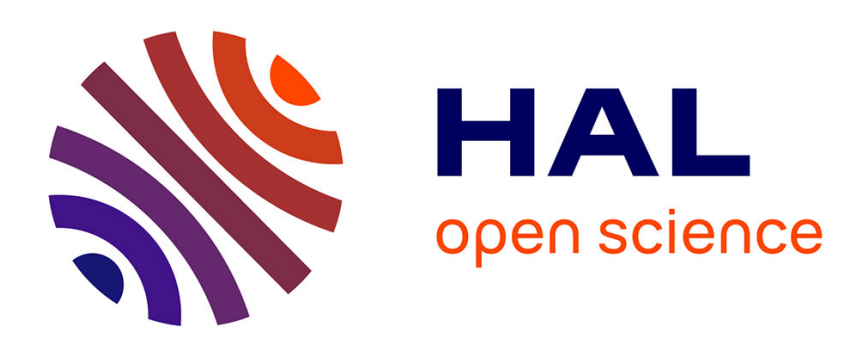

\title{
TEM investigation of rapidly quenched metastable $\gamma$ TiAl phases
}

G. Shao, T. Grosdidier, P. Tsakiropoulos

\section{To cite this version:}

G. Shao, T. Grosdidier, P. Tsakiropoulos. TEM investigation of rapidly quenched metastable $\gamma$ TiAl phases. Journal de Physique IV Proceedings, 1993, 03 (C7), pp.C7-465-C7-468. 10.1051/jp4:1993774 . jpa-00252194

\section{HAL Id: jpa-00252194 https://hal.science/jpa-00252194}

Submitted on 1 Jan 1993

HAL is a multi-disciplinary open access archive for the deposit and dissemination of scientific research documents, whether they are published or not. The documents may come from teaching and research institutions in France or abroad, or from public or private research centers.
L'archive ouverte pluridisciplinaire HAL, est destinée au dépôt et à la diffusion de documents scientifiques de niveau recherche, publiés ou non, émanant des établissements d'enseignement et de recherche français ou étrangers, des laboratoires publics ou privés. 


\title{
TEM investigation of rapidly quenched metastable $\gamma$ TiAl phases
}

\author{
G. SHAO, T. GROSDIDIER and P. TSAKIROPOULOS \\ Department of Materials Science and Engineering, University of Surrey, Guildford Surrey GU2 5XH, U.K.
}

\begin{abstract}
The microstructural characteristics of rapidly solidified Ti-48.8at\%Al-2.2at\%V thin ribbons have been studied. Different forms of the $\gamma$ phase were observed and disordered $\gamma$ is reported for the first time. Thermal APBs associated with the ordering process were observed. $\alpha_{2}$-free domains consisting of $L 1_{0} \gamma$ laths were also investigated. Within the domains, the parallel $\gamma$ laths are at $90^{\circ}$ to one another around $<100>$.
\end{abstract}

\section{INTRODUCTION}

The Ti-Al phase diagram is characterized by successive peritectic reactions $(\mathrm{L}+\beta \rightarrow \alpha$ ano subsequently $\mathrm{L}+\alpha \rightarrow \gamma)$ that spread over a narrow range of temperature for near equiatomic $\mathrm{Ti}$ - $\mathrm{Al}$ alloys [1,2]. Solidification studies carried out in binary Ti-(40 to 70 at\%) $\mathrm{Al}$ alloys have shown that several phases (stable and metastable) are accessible with different bulk undercooling $[3,4,5]$. Microstructural characterization of a Ti-48.8at\% Al-2.2at\% V alloy has shown that $\alpha$ was selected as the first phase during solidification under low cooling rates while $\gamma$ was selected as the first phase at sufficiently high cooling rates [6]. This work reports the microstructural features of sub-30um thick melt spun Ti-48.8at\%Al-2.2at\%V alloy ribbons.

\section{EXPERIMENTAL PROCEDURE}

The TiAl-V alloy was arc melted in a cold hearth and casted on a water cooled copper wheel under high purity argon atmosphere to obtain ribbons with low contamination [6]. The different sub-30pm thick melt spun ribbons investigated in this study were all processed under the same conditions. TEM thin foils were prepared by ion beam thinning either on one side or both sides of the ribbons.

\section{RESULTS}

The microstructure of the thin ribbons varied extensively due to differences in local undercooling and cooling rate associated with different local heat transfer conditions (quality of the wheel/melt contact, variation in local ribbon thickness). Figure 1a shows equiaxed microtwinned $\gamma$ grains observed at the wheel side of a $20 \mu \mathrm{m}$ ribbon. Figure $1 \mathrm{~b}$ shows the [lll 111 l] CBED pattern obtained from the microtwinned $\gamma$ phase, exhibiting a threefold symmetry. This means that the $\gamma$ grains are disordered and of cubic symmetry. At the wheel side of the 20 $\mu \mathrm{m}$ ribbons, some other $\gamma$ grains exhibited a very fine mottled structure (figure $2 \mathrm{a}$ ). SAD patterns of this area showed extra spots at all $\mathbf{L} 1_{0}$ forbidden positions. An example of this is shown in figure $2 \mathrm{~b}$. This suggests that the fine mottled structure is composed of fine cells of antiphase domains associated with the nucleation of the different $\mathrm{L} 1_{0} \gamma$ variants from the parent disordered $\gamma$ phase. The wheel side microstructure of a ribbon around $30 \mu \mathrm{m}$ in thickness is shown in figure $3 \mathrm{a}$. It was completely composed of $\mathrm{Ll}_{0} \gamma$ phase and exhibited twins and patches of a fine lath structure. Microdiffraction pattems from adjacent laths in the $\alpha_{2}$-free patches showed that 
the laths were oriented at $90^{\circ}$ to one another around the $\langle 100>$ directions (figures $3 \mathrm{~b}$ and $3 \mathrm{c}$ ). These lath structures are similar to the ones observed in most of the segregated interdendritic areas in rapidly quenched $150 \mathrm{pm}$ thick ribbons of the same alloy [6]. In the present case however, the patches were located in different places through the grains. The orientation relationship between the $\gamma$ laths agrees with that of the massively transformed $\gamma$ plates reported by Wang et al who investigated the massive $\alpha \rightarrow \gamma$ transformation by quenching a Ti-48at\% Al alloy from the $\alpha$ phase field [7]. The midsection microstructure of a $30 \mu \mathrm{m}$ ribbon is shown in figure 4a. It is composed of cellular $L 1_{0} \gamma$ with intercellular segregates mainly of $\alpha_{2}$ phase (figure $4 \mathrm{~b}$ ).

\section{DISCUSSION}

Formation of the $\gamma$ phase from the melt in rapidly solidified nearly equiatomic TiAl alloys, where $\alpha$ is the equilibrium phase to form from the melt, has been reported by Hall and Huang [5]. Contrary to their interpretation, Jones and Kaufman [8] considered that this $\gamma$ phase was the result of the massive $\alpha \rightarrow \gamma$ transformation. In this paper we show the formation of $\gamma$ from the melt in the case of a TiAl-V alloy where $\alpha$ is also the first phase to form from the melt under low cooling rates [6].

Although the formation of disordered $\gamma$ has been suggested by pyrometric measurement of thermal recalescence events in Al rich TiAl where gamma is the equilibrium phase to form from the melt [4], direct observation of disordered $\gamma$ has not been reported previously, even in rapidly solidified TiAl alloys. Evidence of subsequent ordering is provided by the observation of an extremely fine network of ordered domains (figure 2). Contrary to the "grown-in" APBs discussed by Jones and Kaufman [8], the ordered domains and associated APBs reported here are associated with the ordering process of the disordered fcc $\gamma$ phase. The fact that different states of $\gamma$ phase (fully disordered, fully ordered and containing a very fine network of ordered domains) were all observed at the wheel side of our ribbons without any noticeable chemical segregation suggests that they represent successive stages in a sequential ordering process. If so, the process is extremely fast. This could be associated with the high APB energy of $\gamma$-TiAl, about $450 \mathrm{erg} / \mathrm{cm}^{2}$ [9], and could explain why the TEM studies by Anderson et al failed to detect any differences in the $\gamma$ phases solidified in the ordered or disordered states [4]. Another fact that suggests the direct formation of $\gamma$ from the melt is the observation of a $\gamma$ lath-free cellular structure (figure 4) and the associated reverse segregation [6].

It is therefore clear that at high cooling rates $\gamma$ can solidify from the melt in this TiAl-V alloy. On the other hand, the patches of $\alpha_{2}$-free lath structures observed in the $\gamma$ grains (figure 3) exhibited the same orientation relationship as that resulted from the massive $\alpha \rightarrow \gamma$ transformation and are thus suggested to be associated with this transformation mechanism. Consequently, it seems that the formation mechanisms of the $\gamma$ phase are strongly dependent on local differences in processing parameters. Further work is in progress to characterize the formation mechanisms of this structure and the nature of such differences.

\section{ACKNOWLEDGEMENTS}

We would like to thank Prof. A.P. Miodownik for stimulating discussions, Prof. J.E. Castle for the provision of research facilities and the Procurement Executive of the Ministry of Defence, U.K., for supporting this work.

\section{VI, REFERENCES}

[1] HUANG S.C. and SIEMERS P.A., (1989), Met. Trans. A, 20A, 1899.

[2] McCULlOUGH C., VALENCIA J.J., LEVI C.G. and MEHRANBIAN R., (1989), Acta Metall., $37,1321$.

[3] VALENCIA J.J., McCULlOUGH C., LEVI C.G. and MEHRANBIAN R., (1989), Acta Metall., 37, 2517.

[4] ANDERSON C.D., HOFMEISIER W.H., and BAYUSICK R.J., (1992), Met. Trans., 23A, 2699.

[5] HALL E.L. and HUANG S.C., (1990), Acta Metall. Mater., 38, 539.

[6] SHAO G., GROSDDIER T. and TSAKIROPOULOS P., (1993), this conference : "EUROMAT93".

[7] WANG Ping, VISWANATHAN G.B., and VASUDEVAN Vijay K., (1992), Met. Trans. A, 690.

[8] JONES S.A. and KAUFMAN M.J., (1993), Acta Metall. Mater., 41, 387.

[9] SCHECTMAN D., BLACKBURN M.J., and LIPSITT D., (1974), Met. Trans. 5, 1373. 

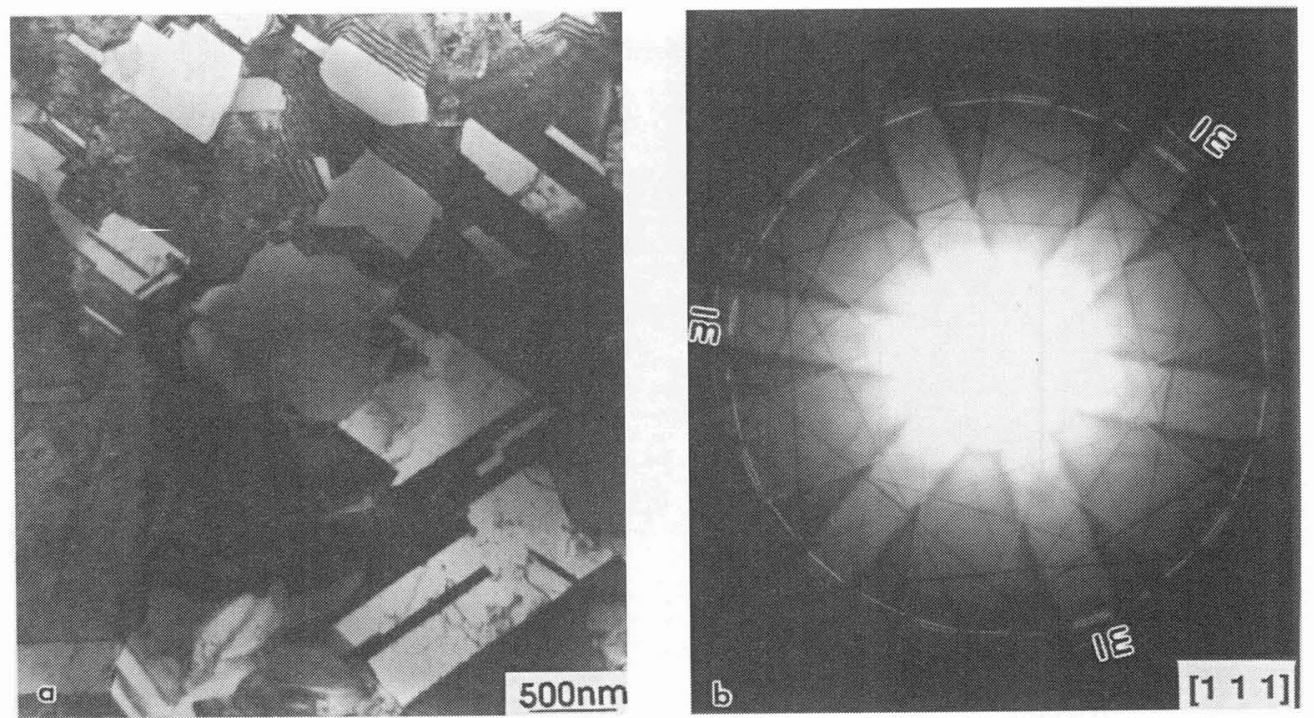

Figure 1: (a) TEM image of twinned $\gamma$ grains observed at the wheel side of a $20 \mu \mathrm{m}$ ribbon. (b) corresponding CBED whole pattern revealing the 3-fold symmetry.
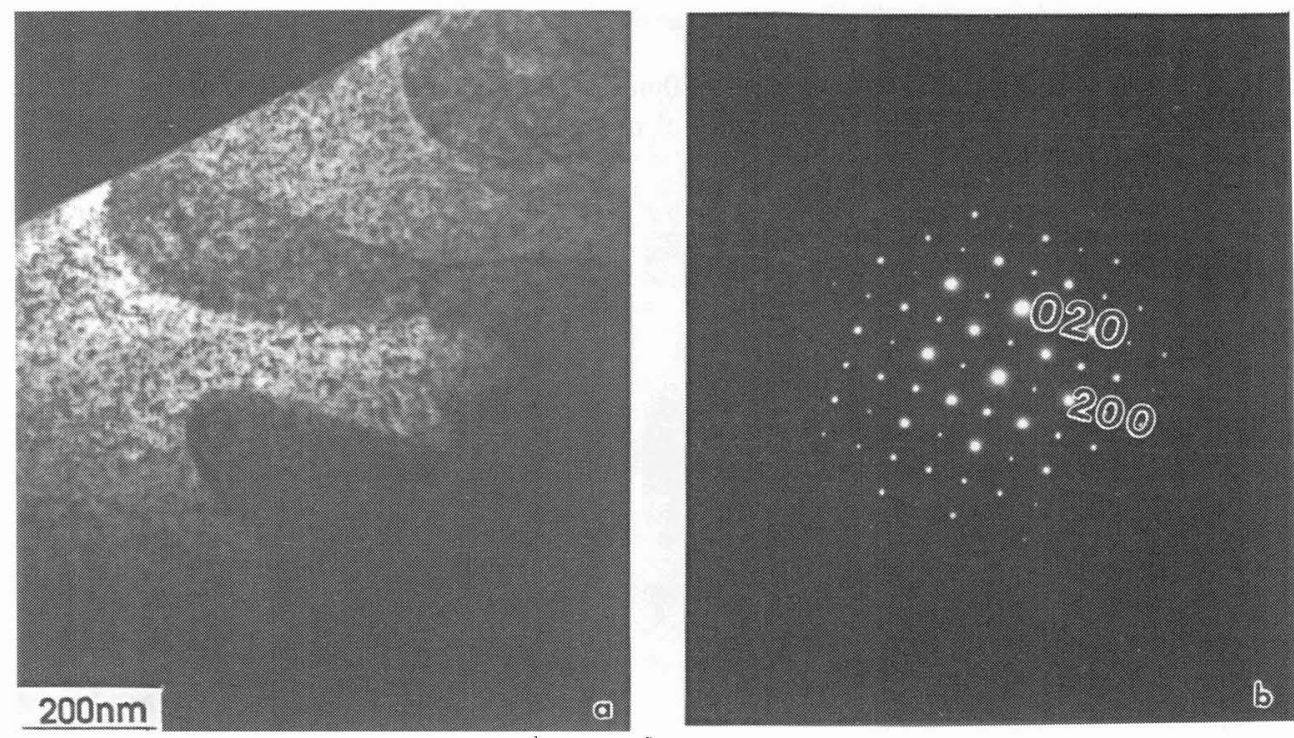

Figure 2: (a) Dark field image of a $\gamma$ grain, exhibiting a fine network of ordered domains. (b) corresponding $<001>$ SAD pattern. 

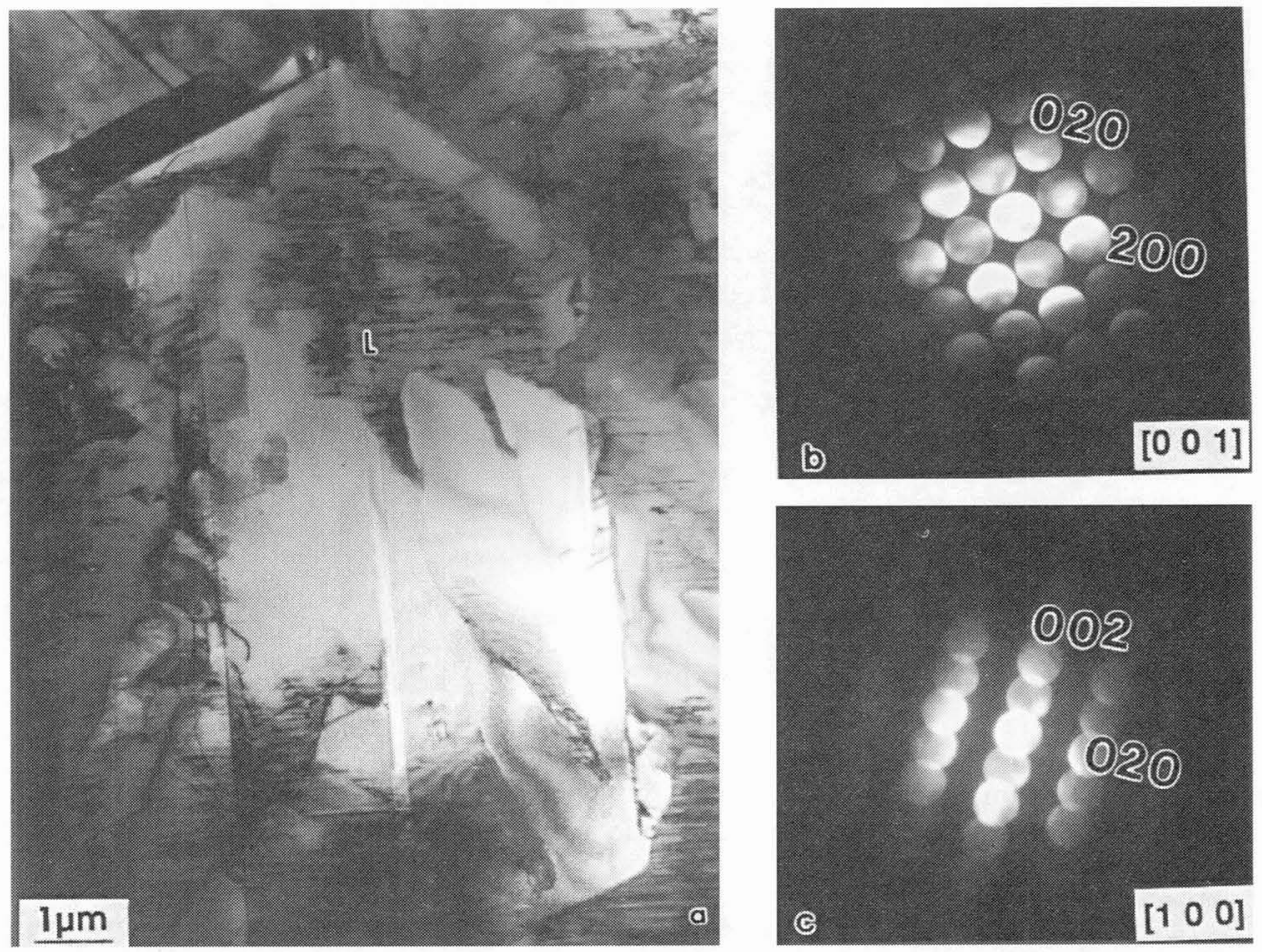

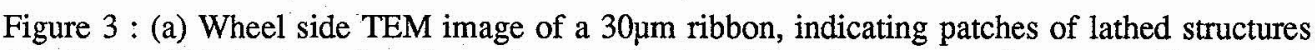
(labelled as ' $L$ ') in the twinned $\gamma$ grains. (b, c) microdiffraction patterns from two adjacent lathes.
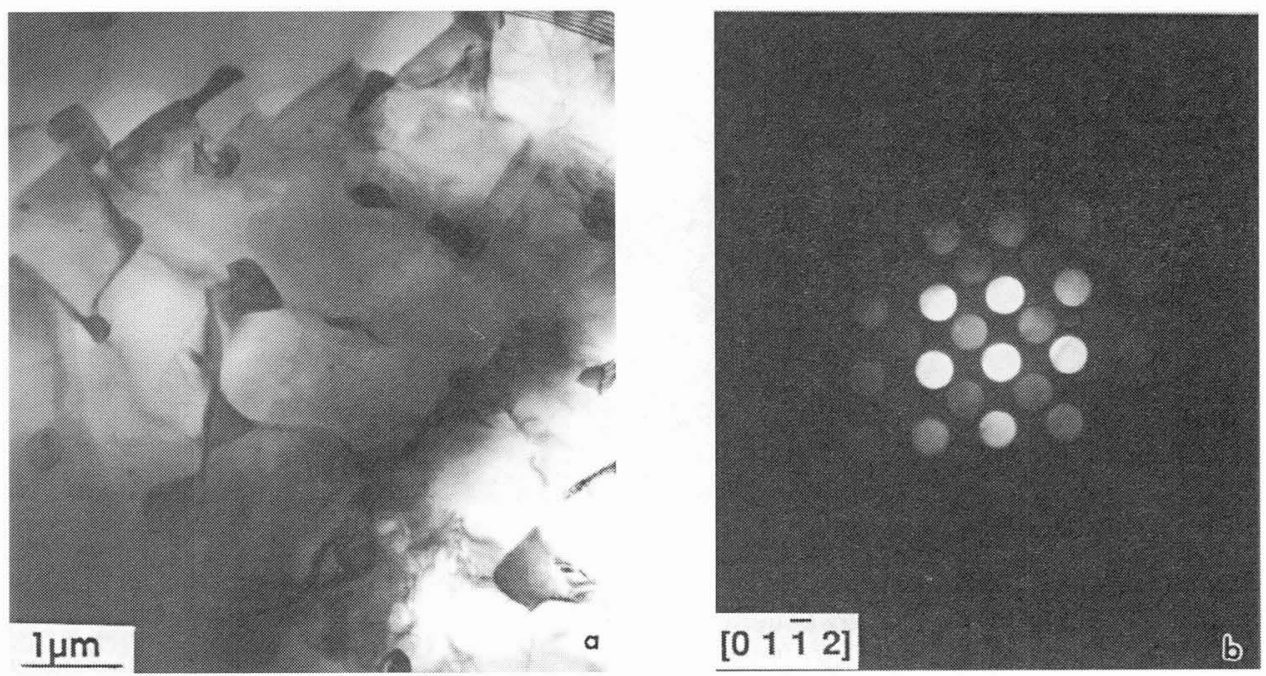

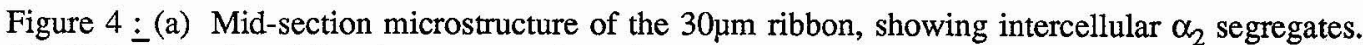
(b) $\left[\begin{array}{lllll}0 & 1 & \overline{1} & 2\end{array}\right]$ microdiffraction pattern of $\alpha_{2}$ phase. 